\title{
EFFECT OF INTRAVENOUS DEXMEDETOMIDINE ON HAEMODYNAMIC AND RECOVERY RESPONSE DURING TRACHEAL EXTUBATION
}

\author{
Gargee Dutta1, N. Das ${ }^{2}$
}

${ }^{1}$ Anaesthetist, Department of Anaesthesiology, Gauhati Medical College.

${ }^{2}$ Professor, Department of Anaesthesiology, Assam Medical College.

ABSTRACT
BACKGROUND
Dexmedetomidine, a highly selective alpha-2 agonist, has various beneficial effects like sedation, analgesia, attenuation of stress
response with minimal cardiovascular instability or respiratory depression and may be a useful agent to facilitate smooth tracheal
extubation.

The aim of this study is to observe the effects of intravenous infusion of Dexmedetomidine in attenuating adverse haemodynamic and recovery response associated with tracheal extubation in patients operated under General Anaesthesia.

\section{METHODS AND MATERIALS}

120 patients were divided into two groups with 60 cases in each group by matching patient's age, sex, Mallampati and ASA grading and randomised with a sealed envelope and divided into two equal groups of 60 each namely group D and group C. Group D and C received an intravenous infusion of dexmedetomidine $0.75 \mathrm{mcg} / \mathrm{kg}$ or placebo respectively, over 15 minutes before anticipated time of end of surgery, Anaesthesia techniques were standardised. Heart rate, systolic, diastolic, mean arterial pressures were recorded while starting injection; at 1, 3, 5, 10, 15 minutes after starting injection; at the time of giving reversal; during extubation; at 1, 3, 5 minutes after extubation; and thereafter every 5 minutes for 15 minutes. Quality of extubation was evaluated on a 5-point scale and postoperative sedation on a 6-point scale. Any event of laryngospasm, bronchospasm, desaturation, respiratory depression, vomiting, hypotension, undue sedation was noted.

Statistical Analysis- Descriptive data presented as Mean \pm SD and in percentage. Pair wise comparison between the groups was done by Student's unpaired t-test. For Qualitative data, Chi-square test was used. Fisher's exact test was used to determine p-value of frequency of complication. P-value $<0.05$ is considered significant.

\section{RESULTS}

Heart rate, systolic, diastolic, mean arterial pressures were significantly higher in group C $(\mathrm{P}<0.05)$. Extubation quality score of majority of patients was 2 in group D and 3 in group C. Sedation score of most patients was 3 in group D and 2 in group C. Bradycardia was higher in group D. One patient in group D, two patients in group C had vomiting.

\section{CONCLUSION}

Dexmedetomidine $0.75 \mathrm{mcg} / \mathrm{kg}$ administered 15 minutes before extubation stabilises haemodynamics and facilitates smooth extubation.

\section{KEYWORDS}

Alpha-2-agonist, Dexmedetomidine, Extubation, Haemodynamics.

HOW TO CITE THIS ARTICLE: Dutta G, Das N. Effect of intravenous dexmedetomidine on haemodynamic and recovery response during tracheal extubation. J. Evolution Med. Dent. Sci. 2017;6(50):3857-3861, DOI: 10.14260/Jemds/2017/833

\section{BACKGROUND}

Management of the airway is central to the practice of anaesthesia. ${ }^{1}$ The tracheal tube is removed (extubation) when it is no longer needed for airway protection. Timing and technique are influenced by balance between the residual effect of anaesthetic drugs and recovery of airway and other reflexes. $^{2}$

Tracheal extubation is almost always associated with haemodynamic changes due to reflex sympathetic discharge caused by epipharyngeal and laryngopharyngeal stimulation.

Financial or Other, Competing Interest: None.

Submission 04-05-2017, Peer Review 10-06-2017,

Acceptance 17-06-2017, Published 22-06-2017.

Corresponding Author:

Dr. Gargee Dutta

House No. 79,

Nripen Borah Path,

Fatasil Ambari, Guwahati-781025.

E-mail: megargeedutta@gmail.com

DOI: $10.14260 /$ jemds $/ 2017 / 833$

(c) (i) $\$$
This increase in sympatho-adrenal activity may result in hypertension, tachycardia and arrhythmias. ${ }^{3,4}$ This increase in blood pressure and heart rate are usually transitory, variable and unpredictable. It is more hazardous to the patient with hypertension, myocardial insufficiency or cerebrovascular diseases. ${ }^{5}$ Respiratory complications at extubation include pulmonary aspiration, upper airway obstruction or hypoventilation leading to hypoxaemia, bronchospasm and laryngospasm. ${ }^{6}$ At the same time, airway irritation appearing during tracheal extubation may cause cough or difficulties in breathing and may contribute to an increase in blood pressure.7,8

Various techniques and antihypertensive drugs are available to attenuate airway and circulatory reflexes during extubation, but none have been completely successful.9,10,11 Attempts have been made to attenuate the pressor response by the use of drugs such as narcotic analgesics, deep anaesthesia induced by inhalational anaesthetics, local anaesthetics, adrenoceptor blockers and vasodilator agents. ${ }^{12}$ 
Alpha-2 agonists are used in modern anaesthesia practice due to their various beneficial effects like sedation, analgesia, attenuation of stress response and reduction in anaesthetic drug requirement. ${ }^{13}$ Alpha-2 agonist decreases the sympathetic outflow and noradrenergic activity, thereby counteracting the haemodynamic fluctuations occurring at the time of extubation due to increase in sympathetic stimulation. ${ }^{14}$

To attenuate airway and pressor response during tracheal extubation, dexmedetomidine, a highly selective alpha-2 adrenoceptor agonist, has been studied as single dose,15,16 at the time of extubation and as an anaesthetic adjuvant.16,17,18,19,20,21

\section{MATERIALS AND METHODS \\ Place of study}

The present study was conducted in the Department of Anaesthesiology, Assam Medical College and Hospital, Dibrugarh for a period of one year.

\section{Design of study}

Randomised controlled trial.

\section{Source of Data}

Patients undergoing elective surgery under general anaesthesia at different operation theatres of Assam Medical College and Hospital, Dibrugarh.

\section{Study Period}

One year from July, 2014 to June, 2015.

\section{Following Criteria were adopted for Selecting Patients Inclusion Criteria}

- Patients aged between 20-50 years of both the sexes.

- Patients scheduled for elective surgeries under general anaesthesia.

Patients with ASA Grade I or II. (ASA Grade I- normal healthy patient, ASA Grade II- patient with mild systemic disease).

\section{Exclusion Criteria}

- Patients with neurological and other endocrine abnormalities.

- Patients with renal impairment and hepatic disease.

- Patients with congestive heart failure, Valvular heart disease, Hypertension, Diabetes Mellitus, and IHD.

- Patients on psychotropic drugs or history of drug allergies.

- Anticipated difficult intubation.

- Previous records of failed intubation.

Patients were selected after thorough pre-anaesthetic assessment and investigations. 120 patients were divided into two groups with 60 cases in each group by matching patient's age, sex, Mallampati and ASA grading and randomised with a sealed envelope and divided into two equal groups of 60 each namely group $\mathrm{D}$ and group $\mathrm{C}$.

\section{Group D}

Dexmedetomidine group. Here dexmedetomidine 0.75 $\mathrm{mcg} / \mathrm{kg}$ body weight in $100 \mathrm{~mL}$ normal saline was infused for
15 minutes before anticipated time of end of surgery.

\section{Group C}

Control group. Here $100 \mathrm{~mL}$ normal saline was infused for 15 minutes before anticipated time of end of surgery.

\section{Procedure}

The patient was pre-oxygenated with $100 \%$ oxygen for 3 minutes before induction with a tight fitting facemask. Anaesthesia was induced with Inj. Propofol ( $2 \mathrm{mg} / \mathrm{kg}$ ) and administered slowly till the loss of eyelash reflex. Inj. Succinylcholine was administered at a dose of 1-1.5 mg/kg IV and maintained on $\mathrm{N}_{2} \mathrm{O}(66 \%)$, oxygen (33\%), isoflurane $(0.5$ - $1 \%$ ) and atracurium (0.5 mg as loading dose and one-fifth as maintenance).

Patients in group D received Dexmedetomidine 0.75 $\mathrm{mcg} / \mathrm{kg}$ body weight in $100 \mathrm{~mL}$ normal saline (NS) infusion for 15 minutes, while in group C patients received $100 \mathrm{~mL}$ NS infusion for 15 minutes before the end of surgery. HR, systolic BP and diastolic BP were recorded at the start of bolus drug injection and also consecutively at 1, 3, 5,10 and 15 minutes. Residual neuromuscular blockades were reversed with Inj. Neostigmine $0.05 \mathrm{mg} / \mathrm{kg}$ and Inj. Glycopyrrolate $0.01 \mathrm{mg} / \mathrm{kg}$ IV. HR, systolic BP, diastolic BP were recorded at the time of giving reversal. When patients' respirations were spontaneous and regular and patients were able to obey simple commands, suctioning and extubation was done. HR, systolic BP and diastolic BP were recorded at the time of extubation and thereafter at 1, 5, 10, 15 minutes after extubation. Occurrence of any event like laryngospasm, bronchospasm, desaturation, respiratory depression, vomiting, hypotension, bradycardia or undue sedation was noted.

Quality of extubation was evaluated based on coughing immediately after extubation, using a 5-point rating scale (Extubation Quality Score). 1 = no coughing, 2 = smooth extubation, minimal coughing ( 1 or 2 times), $3=$ moderate coughing ( 3 or 4 times), 4 = severe coughing (5-10 times) and straining, $5=$ poor extubation, very uncomfortable (laryngospasm and coughing $>10$ times). Postoperative sedation was evaluated on a 6-point scale.

An observation was made related to adverse effects of drugs and anaesthesia related problems and were attended appropriately. Bradycardia was defined as heart rate less than 60 per minute and was corrected with IV atropine 0.6 mg IV when heart rate went below 50 per minute. Hypotension was defined as a decrease in mean arterial pressure of less than $60 \mathrm{mmHg}$ and was corrected with IV fluids and if required, with small dose of mephentermine 3 mg IV.

\section{Statistical Analysis}

Descriptive data presented as Mean \pm SD and in percentage. Pair wise comparison between the groups was done by Student's unpaired t-test. For Qualitative Data Chi-Square test was used. Fisher's exact test was used to determine $p$ value of frequency of complications. For all tests $p$ value of less than 0.05 was considered significant. Microsoft Excel and Microsoft Word have been used to generate graphs and tables. 


\section{RESULTS}

1. Demographic Profile of the Two Groups-

\begin{tabular}{|c|c|c|}
\hline & Study & Control \\
\hline Age & $34.98 \pm 8.77$ & $34.22 \pm 10.07$ \\
\hline Weight & $58.08 \pm 6.00$ & $58.08 \pm 6.00$ \\
\hline \multirow{2}{*}{ Sex } & Male $=35 \%$, & Male $=33.33 \%$, \\
& Female $=65 \%$ & Female $=66.67 \%$ \\
\hline \multicolumn{2}{|c|}{ ASA I and II } & I and II \\
\hline
\end{tabular}

\section{Graphs Showing Haemodynamic Parameters}
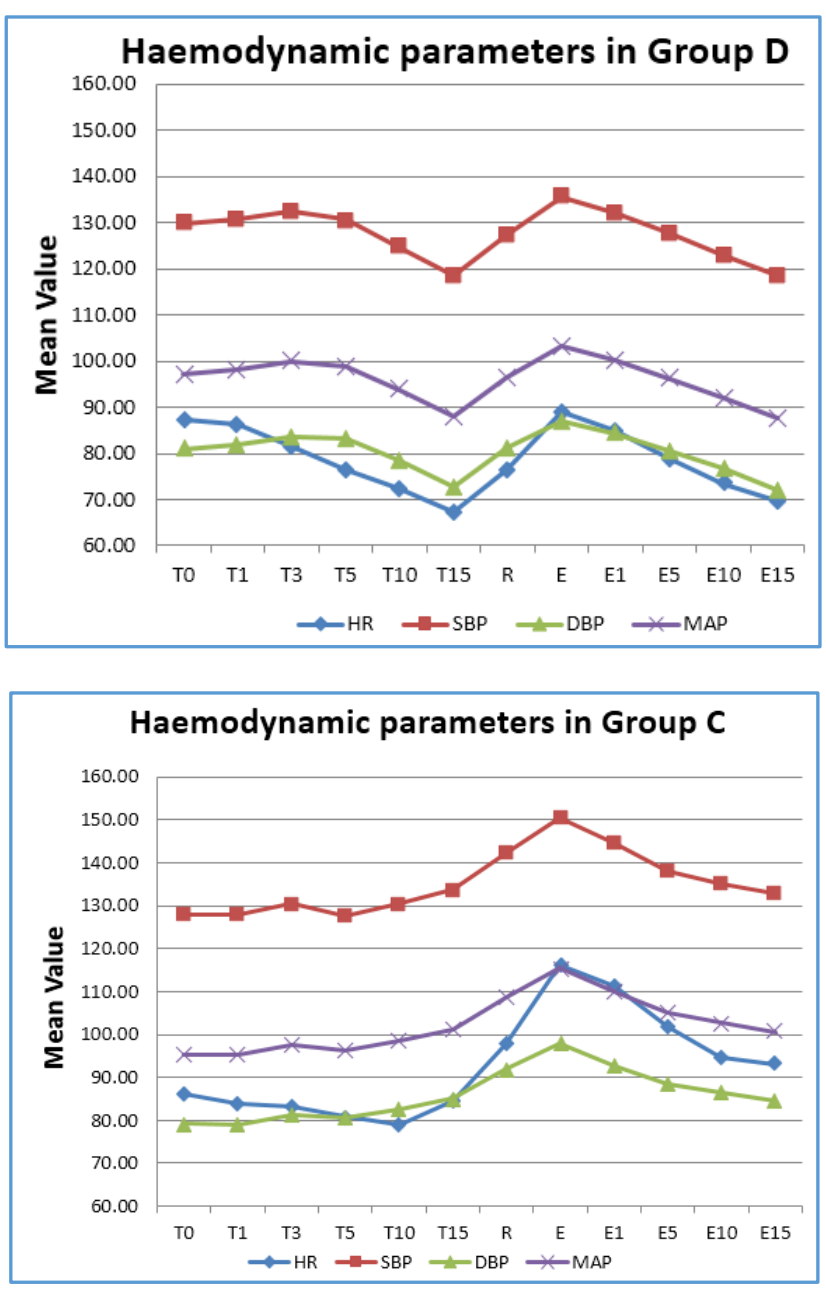

\begin{tabular}{|c|c|c|c|c|}
\hline \multirow{2}{*}{$\begin{array}{c}\text { Extubation } \\
\text { Quality Score }\end{array}$} & \multicolumn{2}{|c|}{ Group D } & \multicolumn{2}{c|}{ Group C } \\
\cline { 2 - 5 } & $\mathbf{n}$ & $\begin{array}{c}\text { \% in } \\
\text { Group }\end{array}$ & $\mathbf{n}$ & $\begin{array}{c}\text { \% in } \\
\text { Group }\end{array}$ \\
\hline 1 & 0 & 0 & 0 & 0 \\
\hline 2 & 44 & 73.33 & 23 & 38.33 \\
\hline 3 & 16 & 26.67 & 37 & 61.67 \\
\hline 4 & 0 & 0 & 0 & 0 \\
\hline 5 & 0 & 0 & 0 & 0 \\
\hline Total & 60 & 100 & 60 & 100 \\
\hline \multicolumn{3}{|c}{ 3. Table Showing Extubation Quality Score } \\
\hline
\end{tabular}

In this study, $73.33 \%$ patients in group D could be extubated smoothly with minimal coughing (Extubation quality score 2 ), whereas $26.67 \%$ patients showed moderate coughing, (Extubation quality score 3). 38.33\% patients in group $\mathrm{C}$ could be extubated smoothly (Extubation quality score 2) whereas $61.67 \%$ showed moderate coughing, (Extubation quality score 3) in group C. So, Dexmedetomidine facilitates a smooth extubation compared with the control group.

\begin{tabular}{|c|c|c|c|c|}
\hline Ramsey & \multicolumn{2}{|c|}{ Group D } & \multicolumn{2}{c|}{ Group C } \\
\cline { 2 - 5 } $\begin{array}{c}\text { Sedation } \\
\text { Score }\end{array}$ & Number & \% in Group & Number & $\begin{array}{c}\text { \% in } \\
\text { Group }\end{array}$ \\
\hline $\mathbf{1}$ & 0 & 0 & 4 & 6.66 \\
\hline $\mathbf{2}$ & 9 & 15.00 & 46 & 76.67 \\
\hline $\mathbf{3}$ & 51 & 85.00 & 10 & 16.67 \\
\hline $\mathbf{4}$ & 0 & 0 & 0 & 0 \\
\hline Total & 60 & 100.00 & 60 & 100.00 \\
\hline
\end{tabular}

4. Table Showing Ramsey Sedation Score

\begin{tabular}{|c|c|c|c|c|c|c|}
\hline \multirow{2}{*}{$\begin{array}{c}\text { Adverse } \\
\text { Effect }\end{array}$} & \multicolumn{2}{|c|}{ Group D } & \multicolumn{2}{|c|}{ Group C } & \multirow{2}{*}{$\begin{array}{c}P \\
\text { Value }\end{array}$} & \multirow{2}{*}{ Significance } \\
\hline & $\mathbf{n}$ & $\begin{array}{l}\text { \% in } \\
\text { Group }\end{array}$ & $\mathbf{n}$ & $\begin{array}{l}\text { \% in } \\
\text { Group }\end{array}$ & & \\
\hline Bradycardia & 6 & 10.00 & 2 & 3.33 & 0.2790 & NS \\
\hline Nausea & 2 & 3.33 & 2 & 3.33 & 1.000 & NS \\
\hline Vomiting & 1 & 1.67 & 2 & 3.33 & 1.000 & NS \\
\hline \multicolumn{7}{|c|}{ 5. Table Showing Adverse Effects } \\
\hline
\end{tabular}

In group D, 6 patients developed bradycardia as compared to 2 patients in the control group, which is statistically not significant. 2 patients in group D and group C developed nausea. Two patients in group $\mathrm{C}$ had vomiting and one patient in group D had vomiting. It is not statistically significant.

\section{DISCUSSION}

There are many adverse changes of haemodynamic and airway following tracheal extubation. Numerous strategies have been used to prevent haemodynamic responses caused by emergence from anaesthesia including extubation under deep anaesthesia, administration of local anaesthetics, vasodilators and short-acting opioids. ${ }^{22}$ Administering vasodilators such as sodium nitroprusside, nitroglycerin, and hydralazine could be associated with complications like reflexive tachycardia and increase in the plasma renin activity. ${ }^{23}$

Dexmedetomidine may be useful as an effective agent for blunting the adverse haemodynamic and recovery response to tracheal extubation.

Dexmedetomidine has been used in different doses in different studies for blunting the adverse haemodynamic and recovery response to tracheal extubation. The dose varied over a wide range in different studies. Most workers used intravenous dexmedetomidine in the range of $0.5-1 \mathrm{mcg} / \mathrm{kg}$ body weight. However, Bindu $\mathrm{b}$ et $\mathrm{al}^{21}$ used a dose 0.75 $\mathrm{mcg} / \mathrm{kg}$, same as our study.

Dexmedetomidine is an alpha- 2 agonist. It is the dextrostereoisomer and active ingredient of medetomidine. It has seven to eight-fold higher affinities for alpha- 2 receptors than clonidine. ${ }^{24}$ Like other alpha-2-adrenergic agonists, it exerts sympatholytic effects by activating inhibitory alpha-2 receptors in both the central nervous system and the peripheral sympathetic nerve endings, inhibiting noradrenaline release. ${ }^{25}$ The inhibition of sympathetic transmitter release can be measured in humans as a decline in the plasma concentration of noradrenaline. ${ }^{26}$ Activation of the receptors in the brain and spinal cord inhibits neuronal firing, causing hypotension, bradycardia, sedation, and analgesia. ${ }^{27}$

IV bolus dexmedetomidine was very effective in attenuating these airway and haemodynamic reflexes without causing any untoward side effect or any other specific 
complication. ${ }^{28}$ Without interfering in recovery time, dexmedetomidine $0.5 \mathrm{mcg} / \mathrm{kg}$ administered $5 \mathrm{~min}$. before the end of surgery stabilises haemodynamics, allows easy extubation, provides a more comfortable recovery and early neurological examination following intracranial operations. ${ }^{15}$ Single-dose bolus injection of dexmedetomidine before tracheal extubation attenuates airway-circulatory reflexes during extubation. ${ }^{16}$ DEX $1 \mathrm{mcg} / \mathrm{kg}$ over 10 minutes, prior to administration of reversal provided haemodynamic stability associated with extubation. ${ }^{14}$ Dexmedetomidine $0.5 \mathrm{mcg} / \mathrm{kg}$ in $100 \mathrm{~mL}$, administered 5 minutes before extubation, and was more effective in attenuating airway reflex responses to tracheal extubation and maintaining haemodynamic stability without prolonging recovery compared with fentanyl 1 $\mathrm{mcg} / \mathrm{kg}$ IV in these patients undergoing rhinoplasty. ${ }^{29}$

In another study, dexmedetomidine was compared with lignocaine and normal saline in extubation and concluded that the use of dexmedetomidine was associated with less increase in HR as compared to lignocaine group, MAP was better controlled in the dexmedetomidine group than in lignocaine group and airway response was better controlled with the use of dexmedetomidine providing a smooth and easy tracheal extubation, thereby a more comfortable recovery and early neurological examination. ${ }^{30}$ In another study, there was a significant decrease in MAP and HR in Dexmedetomidine group as compared to group Lignocaine and group Placebo $(\mathrm{p}<0.05)$ at all-time interval after extubation. Extubation quality score of the majority of patients was 1 in group DEX, 2 in group Lignocaine and 3 in group Placebo. ${ }^{31}$

In our study, most of the patients could be extubated smoothly with minimal coughing (Extubation quality score 2), whereas in control group most of the patients showed moderate coughing, (Extubation quality score 3). Dexmedetomidine facilitates a smooth extubation compared with the control group. This finding is similar to most of the above studies where they found dexmedetomidine facilitates a smooth extubation.

We compared the sedation profile of patients of both the groups on the basis of Ramsay Sedation Score. We found that most patients in dexmedetomidine group were drowsy but responding to verbal commands (Ramsay Sedation Scale 3) after extubation when compared to control group, where most patients belonged to Ramsay Sedation Scale 2. It is due to sedative and anxiolytic properties of dexmedetomidine.

The incidence of bradycardia was higher in group D compared to group C. 6 patients in group D developed bradycardia as compared to only 2 patients in the control group, but their p-value was insignificant. None required treatment as no patient had heart rate below 50 beats per minute. 2 patients in group D and group C developed nausea. Two patients in group $\mathrm{C}$ had vomiting and one patient in group D had vomiting. The incidence of PONV was almost similar in both the groups. None of the patients in either group had any of the other side effects like hypotension, respiratory depression, laryngospasm, bronchospasm or undue sedation.

\section{CONCLUSION}

Dexmedetomidine $0.75 \mathrm{mcg} / \mathrm{kg}$ administered 15 minutes before extubation stabilises haemodynamics and facilitates smooth extubation.

\section{REFERENCES}

[1] Pollard BJ, Norton ML. Principles of airway management. In: Thomas HEJ, Paul KR, (edr). Wyle and Churchill Davidson's a practice of anaesthesia. $7^{\text {th }}$ edn. London: Arnold 2003:P 443.

[2] Peterson GN, Domino KB, Caplan RA, et al. Management of the difficult airway: a closed claims analysis. Anesthesiology 2005;103(1):33-9.

[3] Nishina K, Mikawa K, Maekawa N, et al. Attenuation cardiovascular responses to tracheal extubation with diltiazem. Anesth Analg 1995;80(6):1217-22.

[4] Fuji Y, Saitoh Y, Takahashi S, et al. Combined diltiazem and lidocaine reduces cardiovascular responses to tracheal extubation and anesthesia emergence in hypertensive patients. Can J Anaesth 1999;46(10):952-6.

[5] Mikawa K, Nishina K, Maekawa N, et al. Attenuation of cardiovascular responses to tracheal extubation: verapamil versus diltiazem. Anesth Analg 1996;82(6):1205-10.

[6] Tanaka A, Isono S, Ishikawa T, et al. Laryngeal reflex before and after placement of airway interventions: endotracheal tube and laryngeal mask airway. Anesthesiology 2005;102(1):20-5.

[7] Cranfield KA, Bromley LM. Minimum alveolar concentration of desflurane for tracheal extubation in deeply anaesthetized, unpremedicated children. $\mathrm{Br} \mathrm{J}$ Anaesth 1997;78(4):370-1.

[8] Miller KA, Harkin CP, Bailey PL. Postoperative tracheal extubation. Anesth Analg 1995;80(1):149-72.

[9] Baraka A. Intravenous lidocaine controls extubation laryngospasm in children. Anesth Analg 1978;57(4):506-7.

[10] Jee D, Park SY. Lidocaine sprayed down the endotracheal tube attenuates the airway-circulatory reflexes by local anesthesia during emergence and extubation. Anesth Analg 2003;96(1):293-7.

[11] Minogue SC, Ralph J, Lampa MJ. Laryngotracheal topicalization with lidocaine before intubation decreases the incidence of coughing on emergence from general anaesthesia. Anesth Analg 2004;99(4):1253-7.

[12] Dyson A, Isaac PA, Pennant JH, et al. Esmolol attenuates cardiovascular responses to extubation. Anesth Analg 1990;71(6):675-8.

[13] Kumar S, Kushwaha BB, Prakash R, et al. Comparative study of effects of dexmedetomidine and clonidine premedication in perioperative hemodynamic stability and postoperative analgesia in laparoscopic cholecystectomy. The Internet Journal of Anesthesiology 2014;33(1).

[14] Jain D, Khan R, Maroof M. Effect of dexmedetomidine on stress response to extubation. The Internet journal of Anaesthesiology 2008;21(2):1-3. 
[15] Turan G, Ozgultekin A, Turan C, et al. Advantageous effects of dexmedetomidine on haemodynamic and recovery responses during extubation for intracranial surgery. Eur J Anaesthesiol 2008;25(10):816-20.

[16] Guler G, Akin A, Tosun Z, et al. Single-dose dexmedetomidine attenuates airway and circulatory reflexes during extubation. Acta Anaesthesiol Scand 2005;49(8):1088-91.

[17] Lawrence CJ, De Lange S. Effects of a single pre-operative dexmedetomidine dose on isoflurane requirements and peri-operative haemodynamic stability. Anaesthesia 1997;52(8):736-44.

[18] Ebert TJ, Hall JE, Barney JA, et al. The effects of increasing plasma concentrations of dexmedetomidine in humans. Anesthesiology 2000;93(2):382-94.

[19] Bekker AY, Basile J, Gold M, et al. Dexmedetomidine for awake carotid endarterectomy: efficacy, hemodynamic profile, and side effects. J Neurosurg Anesthesiol 2004;16(2):126-35.

[20] Tanskanen PE, Kytta JV, Randell TT, et al. Dexmedetomidine as an anaesthetic adjuvant in patients undergoing intracranial tumour surgery: a double-blind, randomized and placebo-controlled study. Br J Anaesth 2006;97(5):658-65.

[21] Bindu B, Pasupuleti S, Gowd UP, et al. A double blind randomized, controlled trial to study the effect of dexmedetomidine on hemodynamic and recovery response during tracheal extubation. Journal of Anaesthesiology 2013;29(2):162-7.

[22] Hohlrieder M, Tiefenthaler W, Klaus H, et al. Effect of total intravenous anaesthesia and balanced anaesthesia on the frequency of coughing during emergence from the anaesthesia. $\mathrm{Br} \mathrm{J}$ Anaesth 2007;99(4):587-91.

[23] Unal Y, Ozsoylar 0, Sariguney D, et al. The efficacy of esmolol to blunt the hemodynamic response to endotracheal extubation in lumbar disc surgery. Res J Med Sci 2008;2(2):99-104.
[24] Carollo DS, Nossaman BD, Ramadhayani U. Dexmedetomidine: a review of clinical applications. Curr Opin Anesthesiol 2008;21(4):457-61.

[25] Langer SZ. Presynaptic regulation of the release of catecholamines. Pharmacol Rev 1980;32(4):337-62.

[26] Scheinin M, Kallio A, Koulu M, et al. Sedative and cardiovascular effects of medetomidine, a novel selective alpha-2-adrenoceptor agonist, in healthy volunteers. Br J Clin Pharmacol 1987;24(4):443-51.

[27] Gertler R, Brown HC, Mitchell DH, et al. Dexmedetomidine: a novel sedative analgesic agent. Baylor University Medical Centre Proceedings 2001;14(1):13-21.

[28] Goarya RS, Mathur A. I/V bolus dexmedetomidine attenuates the airway reflexes and hemodynamic responses during extubation following general anaesthesia JEMDS 2014;3(65):14114-28.

[29] Aksu R, Akın A, Biçer C, et al. Comparison of the effects of dexmedetomidine versus fentanyl on airway reflexes and hemodynamic responses to tracheal extubation during rhinoplasty: a double-blind, randomized, controlled study. Current Therapeutic Research 2009;70(3):209-20.

[30] Sharma VB, Prabhakar H, Rath GP, et al. A study on comparison of dexmedetomidine and lignocaine on attenuation of airway and pressor responses during tracheal extubation. Journal of neuroanaesthesiology and critical care 2014;1(1):50-5.

[31] Gosai ND, Jansari AH, Solanki RN, et al. A comparative study of the effect of dexmedetomidine and lignocaine on hemodynamic responses and recovery following tracheal extubation in patients undergoing intracranial surgery. International Journal of Basic \& Clinical Pharmacology 2015;4(2):371-5. 